\title{
Using Geographic Information Systems to develop decision support system for supplier selection in batik industry
}

\author{
Aries Susanty ${ }^{1}$, Sri Hartini ${ }^{2}$, Diana Puspita Sari ${ }^{3}$, Prilliandi Hidayatullah ${ }^{4}$ \\ ${ }_{1,2,3,4}$ Department Industrial Engineering, Diponegoro University, Indonesia
}

\begin{abstract}
This study has two purpose. First, this study aims to analyse the requirements of batik industry on effective and powerful software to select their supplier effectively. Second, this study aims to design, build, and test a web-based decision support system that using Geographic Information System (GIS) to select the best supplier for particular raw material. A prototype approach is used as a method for developing a web-based decision support system and several SMEs and supplier of batik industry in Central Java and Jogjakarta is used as a preliminary of object for proposed web-based decision support system. Thus, after the initial prototype of an information system was developed, this study use acceptance sampling with alpha and beta testing and also use system testing with positional accuracy testing as a tool for revising and enhancing the initial prototype. The result of all of those testing indicate that application of supplier selection based on GIS in the batik industry has been successfully used and did not experience an error, satisfied the user need and there was no differences between the coordinate of selected starting and ending point from GIS with the coordinate of selected starting and ending point from Global Position System (GPS).
\end{abstract}

Keywords: Batik Industry, Central Java, Supplier Selection, Geographic Information System, Web-based decision support system, Yogyakarta,

\section{Introduction}

Small-to-medium-sized enterprises (SMEs) play an essential role in the economy. In Indonesia, the portion of the contribution of SMEs to the domestic GNP is about $57.94 \%$ and it increased to $59.08 \%$ (or equal to USD 347.8 trillion) in 2012. Then, related to Indonesia's export performance, in 2010, the value of export from Indonesian SMEs contribute USD 12.5 billion (equal to 15.81\%) to national export performance and USD 13.3 billion (equal to $16.44 \%$ ) in 2011. Besides have essential role in economy, SMES also a major source of employment, entrepreneurial skills and innovation (Rezaei, 2012). Indonesia SMEs grow as much as $2.41 \%$ of the total 55,206,444 units in 2011-2012. In 2011, SMEs created jobs to about 97.24\% (equal to 101,722,548 persons) and in 2012, SMEs had successfully created jobs to about $9.16 \%$ (equal to 107,657,509 persons) (Hanny, 2014).

According to Nooteboom (1994), there were several characteristics of SMEs that differentiated this organization with the larger enterprise. These characteristics are including intertwined ownership and management, integration of tasks in worker, variation and improvisation, few hierarchical levels, short communication lines, few and simple procedures, personal, direct, oral internal communication, personal and close relations with customers, craftsmanship, tacitness of knowledge, and idiosyncratic perception, few products and markets, small volume of production, no staff functionaries, lack of managerial time, much authority and many functions in one hand, low level of abstraction product-or technique orientation, and possible lack of finance. Then, according to Gunasekaran et al (2000), the cost structure of an SME is different from larger enterprises; SME production is characterized by relatively high wages costs, but they spend less (compared to larger enterprises) on raw material, semi-finished products, and other products and services supplied to them (Gunasekaran et al, 2000). Thus, one of the primary goals of the strategies adopted by SMEs is to be flexible on the procurements in-order to save as much as possible on the supplies without compromising quality and delivery time aspects. Because of their small size, the autonomous agents in-charge of procurement, can be more agile (without time-consuming internal consultations) in responding to newer opportunities, e.g. selection suppliers with better bids (Davidrajuh, 2001).

To get the supplier with better bids, basically, the SMEs need inexpensive but effective and powerful software to select their supplier effectively. According to this situation, this research aims to develop the internet-based or web-based application for supplier selection in SMEs, especially for SMEs batik. The internet or World Wide Web allows enterprises from the smallest enterprise to largest corporations to establish global presence. Hence, small enterprise now have the opportunity to reach geographically dispersed markets that would otherwise been cost prohibitive to consider. SMEs also now have the opportunity to select the best suppliers, by utilizing suppliers' bids on WWW, thus averting time consuming and costly outside sources (or middlemen) like professional contacts, trade journals, directories, and import brokers. The best supplier is mean the supplier who can supply an SME with right amount of material at the right time - thus preventing physical 
inventories at the SME, at right price (or cheap) of the right quality (for example, by adhering to ISO standards) (Davidrajuh, 2000). Despite there were so many web-based application for helping the SMES, this research focus on development a web-based decision support system that has two functions: the first function, a webbased decision support system will use Geographical Information Systems (GIS) to find several nearby supplier of a particular raw material in a particular geographic area, and the second function, a web-based decision support system will indicate the best supplier based on the minimum cost of delivery. So, based on this condition, this study aims to: (i) analyze the requirements of batik industry on effective and powerful software to select their supplier effectively; and (ii) design, build, and test a web-based decision support system that using GIS to select the best supplier for particular raw material.

The rest of the paper is organized as follows. The following section will be consist of the relevant literature about criteria for supplier selection, GIS and Google Map API. This is followed by methodology of research which includes the steps of application development. Then the result of analyzing the requirements of batik industry on effective and powerful software and the result of application development will be explained in the next section. Finally, the last section will be consist of a summary of the findings and some limitation of the study.

\section{A. Criteria for Supplier Selection}

\section{Literature Review}

To persist in the strongly competitive market, it is often critically important to not only develop current suppliers but also to find a new suppliers. In this case, to find a new supplier, firm usually need to select appropriate suppliers that can provide faster delivery, reduced cost and improved quality in order to increase corporate competitiveness and additionally searching for those suppliers and continuously assessing their performance are critical supply chain activities (Yang and Chen, 2006). This condition make the decision making process of selection of new supplier can be a complicated process since there is so many criteria that must be considered (qualitative and quantitative criteria or tangible and intangible criteria) and each criteria can have conflict each other's. Besides that, the firms usually have internal and external constrains imposed on buying process (Vera and Pullman, 1998).

Dickson (1966) introduced 23 criteria for supplier selection in his publication. The study was enhanced by Weber et al (1991) by reviewing 74 publications from 1966 to 1990. Then, Zang et al (2003) make a comparison between study conducted by Dickson and Weber et al, and they summarized a new criteria for supplier selection from the study of 49 articles from 1992 to 2003. Besides Zhang et al (2013), the study literature about supplier selection also conducted by Fawcett and Magnan (2001), Ho et al (2010), Mwikali and Kavale (2012) and Kar (2014). Some of criteria for supplier selection can be described as follow.

- Quality. According to Ho et al (2010), quality is the first most popular criteria for supplier selection. According to Beamon (1999), quality criterion has been measured on the basis of the importance of the following quality dimensions: management commitment, process improvement of suppliers, quality planning and quality assurance in supply chain, quality assessment in production, inspection and experimentation and quality staff of supplier (Beamon, 1999). Then, according to Ho et al (2010), there were several attributes related to quality, such as acceptable parts per million, compliance with quality, low defect rate, net rejections, etc.

- Delivery. Delivery is the second most popular criterion in the supplier selection (Ho et al, 2010). Its related to the ability of the supplier to follow the predefined delivery schedule. This means that suppliers who keep their promises are easier and profitable to work with (Fawcett and Magnan, 2001; Mwikali and Kavale, 2012).

- Cost/price. Price/cost is not the most widely adopted criterion. Cost/price is only the tird most popular criterion in the supplier selection (Ho et al, 2010). The aim of this criterion is to identify the cost related with a product, such as cost for making a transaction, transportation cost and taxes, and cost for improper product, etc. Purchasing price can be part of cost criterion or become an independent criterion (Fawcett and Magnan, 2001; Mwikali and Kavale, 2012)

- Lead time. Lead time can be defined as the time between the order release by the firms and the material or product delivered by suppliers. The firm usually like supplier that can deliver the material in a sort time. The shorter the lead time, the better the supplier (Fawcett and Magnan, 2001; Mwikali and Kavale, 2012).

- Ease of Communication. The ease of communication and negotiability with the suppliers are one of the important factor in deciding the long-term relation between the firms and suppliers. The good suppliers should have best communicators and can be deliver the good message in good time (Fawcett and Magnan, 2001; Mwikali and Kavale, 2012).

- Performance history. The performance history of the supplier should be analyzed carefully keeping in mind the competitive nature of the supplier, its past production schedule, response to market, and its ability to make commercial relations and business references. It is easy to get a profile of ageing supplier easier than 
new suppliers. Research shows that, old suppliers are more experienced and more stable in business (Kibe, 2000).

- Geographical Location. The location of the supplier and its physical and social status should be analyzed properly before selection of global partner (Fawcett and Magnan, 2001; Mwikali and Kavale, 2012). Geographical location is a preferred criterion as it will decide whether to engage a local or distant supplier which will ultimately have an impact on purchasing costs of raw material. Of course, price offered and quality were still the important criteria, but knowing the location of suppliers who can provide raw material with desired price and quality were also important and this can reduce the cost of production (Jain et al, 2013).

\section{B. Geographical Information System and Google Map API}

In the last decade, Geographical Information System (GIS) has become an important tool for planning and making strategic decision based on information system. There were numerous definition of GIS. The first definition of term of GIS as a decision support system was made by Cowen (1988). A GIS is a decision support system involving the integration of spatially referenced data in a problem-solving environment. Then, Star and Estes (1990) defined GIS as an information system that is deliberate to work with data referenced by spatial or geographic coordinates. In other words, a GIS is both a database system with specific capabilities for spatiallyreferenced data, as well as a set of operations for working with the data. The other definition of GIS came from Christiansen (1998). A GIS is a system, consisting of hardware, software, data, procedures and a proper organizational context which compiles, stores, manipulates, analyses, models and visualizes, spatial data, to solve planning and management problems. According to Selamat et al (2012), basically, GIS can be divided into three parts of definition, a computer based, dynamic mapping system with spatial data processing, and the ability to query. Clearly, GIS is a computer technology and a dynamic system controlled by human. The system allows us to organize and view the map, change the colors, symbols, and labels, zoom the map to get detailed information, change the layer map, and obtain data that was recorded. Users of the system can put the dots on the map from scratch and be able to perform data query (Selamat et al, 2012). Fundamentally, a GIS is a tool for linking attribute databases with digital maps. GIS also provides users with advanced modeling functions, tools for design and planning, and advanced imaging capabilities. While many of these capabilities also exist in other types of systems, such as visualization and virtual reality systems, GIS is unique because of their emphasis on providing users with a representation of objects in a cartographically accurate spatial system and on supporting analysis and decision-making (Mennecke, 2000)

GIS can be used in the level national or level company. In level national, for example, GIS usually used by federal, state, and local governments for assessing and planning such areas as land use, healthcare, housing, natural resources, transportation, and environmental monitoring. In the level of companies, GIS usually used for expand and consolidate their business, make market analysis, or to find the best delivery routes for distribution of their product (Longley et al, 1999). Specifically for supply chain analysis, GIS is used as a tool for addressing logistics and transportation problems.

According to Peng and Tsou (2003), since the emergence of the internet in the 1990s, the internet has affected GIS in three major areas: GIS data access, spatial information dissemination and GIS modelling/processing. In this case, access to and transfer of spatial data over the internet are the first steps toward true internet GIS and the use of Google Maps Application Programming Interfaces (API) has been shown to have great potential as GIS software for developing Internet GIS solutions (Chow, 2008). Google Maps is a free web map server application and technology provided by Google that powers many map-based services. The user can also control the map with the arrow keys to move to the desired location. To allow for quick movement, the "+" and "-" keys can be used to control the zoom level. Users may enter an address, intersection or general area to quickly find it on the map. Google Maps offers three viewing modes by default: Map (Street map views), Satellite (satellite and high-resolution aerial photographs) and Hybrid (Street maps overlaid on satellite and high-resolution aerial photographs) (Gomez, 2007). To use Google maps, the first step is doing registration to get the API key from Google that will be used in the program code. Registration can be done through http://www.google.com/apis/maps/signup.html. It would be better if a programmer has to know web programming language, such as HTML, XML, and Java Script because JavaScript is the native language of Google Maps and Google Maps is built of XHTML (Extensible HTML), formatted with CSS (Cascading Style Sheet) (Udell, 2009)

\section{Study Region}

\section{Method of Research}

There were several SMEs and supplier of batik industry in Central Java and Jogjakarta attached in the proposed web-based decision support system as a preliminary of object for this application. It is because Central Java and Yogyakarta are three two main region of batik craft's industries in Indonesia. The Central Java export 
Using Geographic Information Systems to develop decision support system for supplier selection in..

batik to USA $\$ 2.175$ million in 2011, rise 9 percent compare to 2010 of at least $\$ 1.992$ million. In Yogyakarta, there were more than 500 motif batik and export batik from Yogyakarta at least US \$36.53 million in 2015.

\section{Data Acquisition}

There were many type of suppliers of raw material for batik industry in Central Java and Yogyakarta. For this study the scope of materials was restricted to only fabric and wax, owing to its importance and availability. Data about supplier of fabric and wax is collected by observation and conduct an interview to the SMEs. There were several data from supplier that must be collected before mapped. The data of supplier is included personal information of suppliers like name and address, details of materials like price of material and cost of transportation.

\section{E. Application's Development}

Basically, there were two function will be develop in this application and prototype approach is chosen as a method for development. The notion of prototyping in system or application development emerged in the late 1970's (Naumann and Jenkins 1982, Bally et al. 1977) as a reaction against more traditional phase-oriented models (e.g. linear models, life-cycle models, waterfall models etc.) of how to develop computer systems (Avison \& Fitzgerald 1988, Bally et al. 1977, Boehm 1988, Hekmatpour \& Ince 1988, Lantz 1986). Graphically, the prototype approach for system or application development can be seen in figure 1. According to that figure, there were four-step in developing application with prototype approach. The first step is identify the user's basic requirement. In this step, the system designer (usually an information systems specialist) works with the user only long enough to capture the user's basic information needs. The second step is developing an initial prototype. In this step, the system designer creates a working prototype quickly, using tools for rapidly generating software. The third and fourth step are using the prototype and revising and enhancing the prototype. In this step, after the prototype has been developed, the end users and clients are given an opportunity to use the prototype and play with it. Based on their experience, they provide feedback to the developers regarding the prototype: what is correct, what needs to be modified, what is missing, what is not needed, etc. Based on the feedback, the prototype is modified to incorporate some of the suggested changes that can be done easily, and then the users and the clients are again allowed to use the system. This cycle repeats until and client are satisfied (Laudon and Laudon, 2002; Ajah and Ugah, 2013)

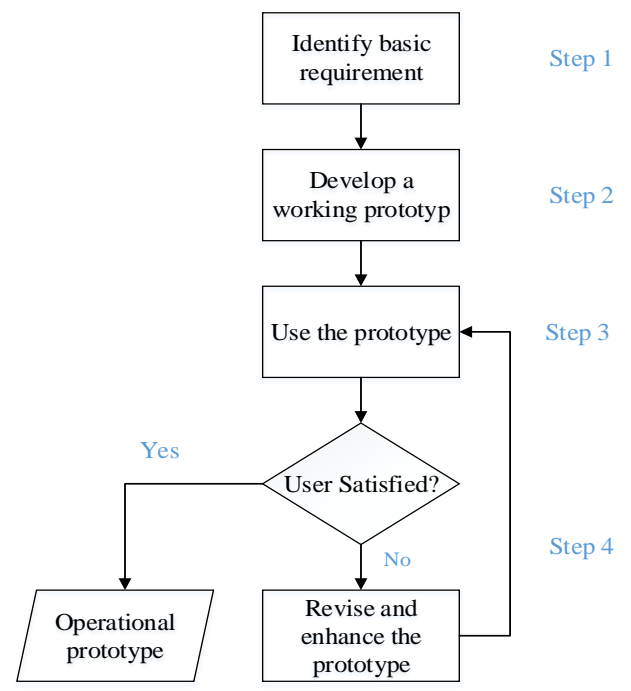

Figure 1. Prototype Approach for System or Application Development (Laudon and Laudon, 2002)

There are some tools used for developing a working prototype, i.e. Use-Case Diagram, Context Diagram, Data Flow Diagram, and Entity Relationship Diagram. Use cases diagrams are a type of UML diagram whose purpose is to define graphically the functionality of a system in terms of actors, use cases and relations (Eichelberger, 2008). They have great importance as a technique for extracting and defining functional requirements from the user point of view (Cockburn, 2000). The context diagram is a top-level view of an information system that shows the boundaries and scope. It describes the main objective of the system and the entities involved (Kapil et al, 2014). The context diagram is used to describe the relationship of input-processoutput between the systems with the outside environment (Satzinger et al, 2010). It represents all the processes that occur in the system. The context diagram was then decomposed into sub-processes or Data Flow Diagram (DFD) (Yakubu et al, 2011). Data Flow Diagram (DFD) was first proposed by Larry Constantine the original 
developer of structured design at 1970s. According to Dixit and Kumar (2008), DFD is a graphical tool that allows system analysts and users to depict the flow of data in an information system. DFD symbols consist of four symbols which are processes, data flows, data stores and external entities. Level 0 DFD represents a system's major processes and usually called as context diagram. Every process in the level n-1 DFD would be decomposed into its lower-level data flow diagram which is level $\mathrm{n}$ data flow diagram. The key principle in data flow diagram is to ensure balancing which means that the data flow diagram at one level is accurately represented in the next level data flow diagram when developing a project (Ibrahim and Yen, 2012). The ideal level of decomposition is to decompose the system until system analysts and users can provide a detailed description of the process whereby the process descriptions is not more than one page. Then, validation should be taken to the final set of DFD to ensure the quality of DFD. In general, the problem in DFD can be divided into two category, i.e. syntax errors and semantics errors. Tao and Kong (1991) defined the syntax of the data flow diagram is how components are interconnected through data flows and what components constitute the subsystem being modeled. On the other hand, the semantics of the data flow diagram is how data flows are interrelated in terms of data transformations. Compared with syntax error, semantics are more complicated because of a set rules that need to be followed in order to identify them. As an example, every process has at least one input data flow and every process has at least one output data flow. Based on this condition, it is important for someone to understand the set of rules for data flow diagrams. Once the rules are understand, a formal model can be developed based on the rules so that the formal model can be used to perform consistency check between context diagram and level 0 data flow diagram. The formal model can guarantee that the correctness and reliability of data flow diagrams can be increased (Ibrahim and Yen, 2011). The entity relationship diagram (ERD) is the standard data technique for creating data models. The ERD enables an analyst to create a graphical view of the data concepts of an organization and their relationships (Arsovski, 2012). The ERD was introduced by Chen in early 1976 (Chen, 1976). The basic components of the ERD are entities, properties of entities called attributes, and relationships between entities

\section{F. Identify Basic Requirement}

\section{Result}

The basic requirement of SMEs is to find the supplier which can supply the SMEs the right amount of material at the right time and at the lowest purchasing cost. For this reason, the SMEs need to know the geographical location of each supplier. In this case, knowing geographical location of each supplier will make the SMEs can choose the closer supplier with their location so the SMEs can minimize the delivery cost which will ultimately have an impact on purchasing costs of raw material. The need of SMEs to know the geographical location of each supplier can be solved by develop a web-based decision support system application that using Geographical Information Systems (GIS) which facilitated by Google Maps.

Thus, there is a number information or database needed to develop those application i.e. the information about each SME, the information about raw material needed, the information about supplier, and the information about availability of raw material. The information about SMEs will be consist of the personal information of SMEs such as the name of SME, the location of SMEs, the type of batik produced, e-mail address, and the phone number. The information about raw material needed by SMEs will be consist of the type of raw material needed (fabric, dye, or wax) and amount of raw material needed. The personal information about each supplier will be consist of the name of supplier, the location of supplier, e-mail address, and phone number. The availability of raw material from supplier (the type and amount of raw material will consist of the price of raw material and the delivery costs of raw material in accordance with the type of transport that will be used, as well as the amount of particular materials to be transported.

Procedures for the supplier selection based on the most minimal delivery costs can be explained as follows. First, the users (SMEs) will see the map of Central Java and Yogyakarta. Then, the users will determine their location on the map as the point of destination for delivery of raw material. In this case, the point of destination can be selected through the menu if the SMEs has been registered in the database; or, SMEs can put the cursor on the map that is expected of their recently location. The SMEs selects the type and the amount of raw material will be purchased. The system will be display delivery path of each suppliers that sell these types of materials to be purchased. Besides that, the system will be display an information about the delivery cost of each supplier based on type transportation which is used to make deliveries.

\section{G. Develop a Working Prototype of a Web-based Decision Support System}

This section will discuss about use case diagram, data flow diagram, entity relationship diagram, interface design, and system evaluation and testing

1) Use Case Diagram, Data Flow Diagram and Entity Relationship Diagram

The use case diagram for supplier selection of raw material in batik industry based on GIS is presented in Figure 1 . 


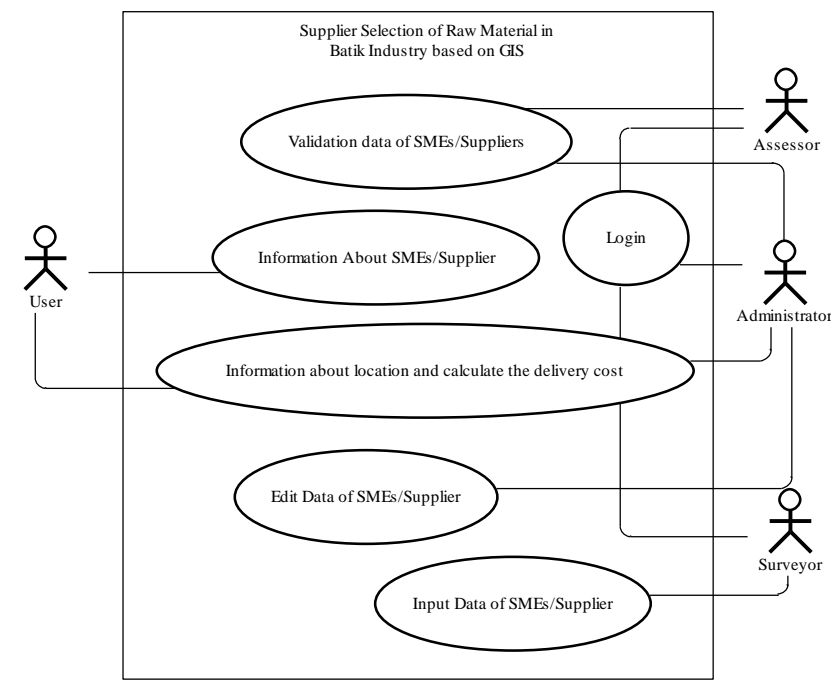

Figure 1. The use case diagram of proposed a web-based decision support system

As it can be seen in that figure, the client of this application consist of four actors who carry out activity on the system, i.e. administrator, surveyor, assessor, and user. Thus, the activity which can be carry out by the actors are included login, getting information about SMEs or supplier, input data of SMEs or supplier, edit data or SMEs or supplier, validation data about SMEs or supplier and getting information about location about supplier and calculate the delivery cost for certain type of raw material. Administrator, surveyor or assessor can be login to the system (or main page) by entering their username and password. Administrator and surveyor can input, edit, and validate the data about SMEs and supplier. User cannot input, edit, or validate the data about SMEs and supplier. User only can see those data. Besides that, the user also can make a comparison the distance between SMEs batik and location of suppliers and delivery cost that will be charged to SMEs Batik.

Context Diagram that shows the system boundaries, external entities that interact with the system and the major information flows between the entities and the system can be seen in Figure 2. The context diagram in figure 2 represents several entities, such as user, assessor, surveyor, and administrator. In this case, each entities supplies some information to the system and after those information processed by the system, the entities can retrieve some information from the system and using it.

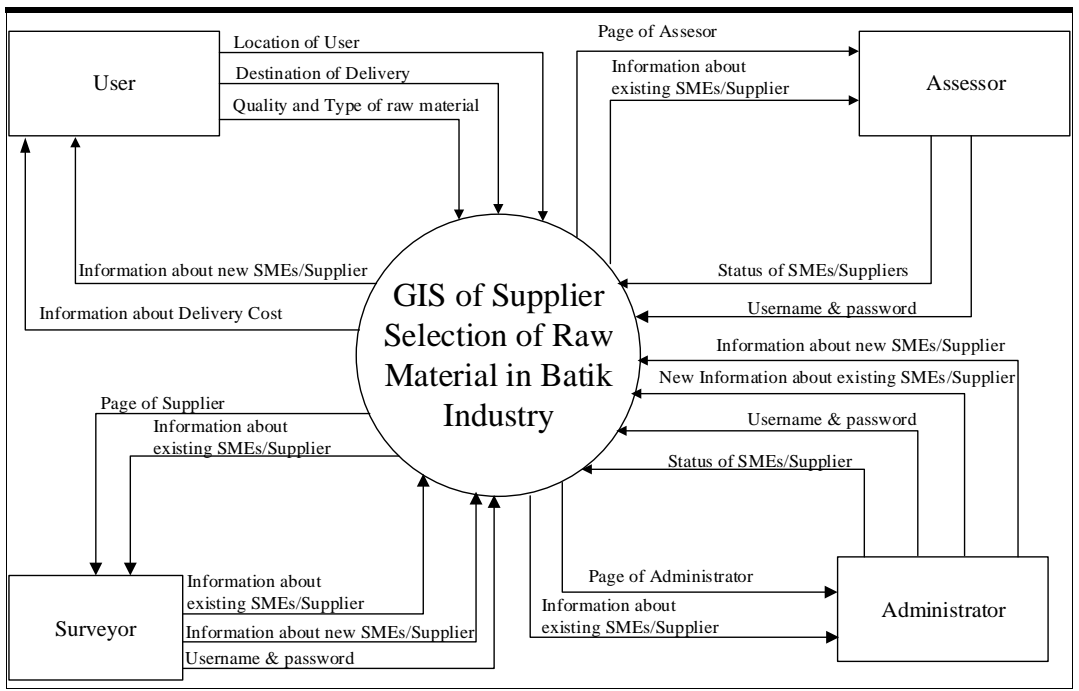

Figure 2. The context diagram of a web-based decision support system

Thus, the context diagram is further decomposed into the lower-level, and each process on the level can be decomposed into more explicit Data Flow Diagrams (DFDs) level 1, DFDs level 2, and DFDs level 3 (see Fig. 3, Fig.4, and Fig. 5). DFD level 1 will describe the processes contained in the GIS of supplier selection of raw material in batik industry, namely login, management of information, and the calculation of delivery costs. Thus, DFD level 2 will describe the details of the process of the management information contained in the DFD level 1; whereas, DFD level 3 will describe the detail process of edit data of SMEs or suppliers. 


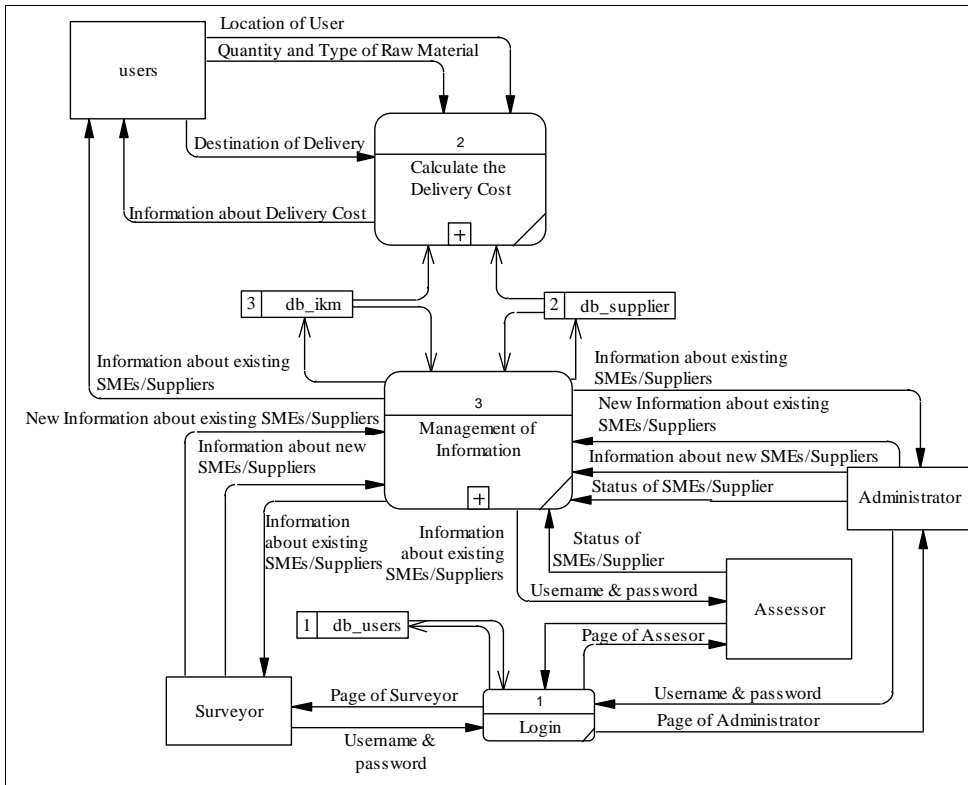

Figure 3. The DFD Level 1of proposed a web-based decision support system

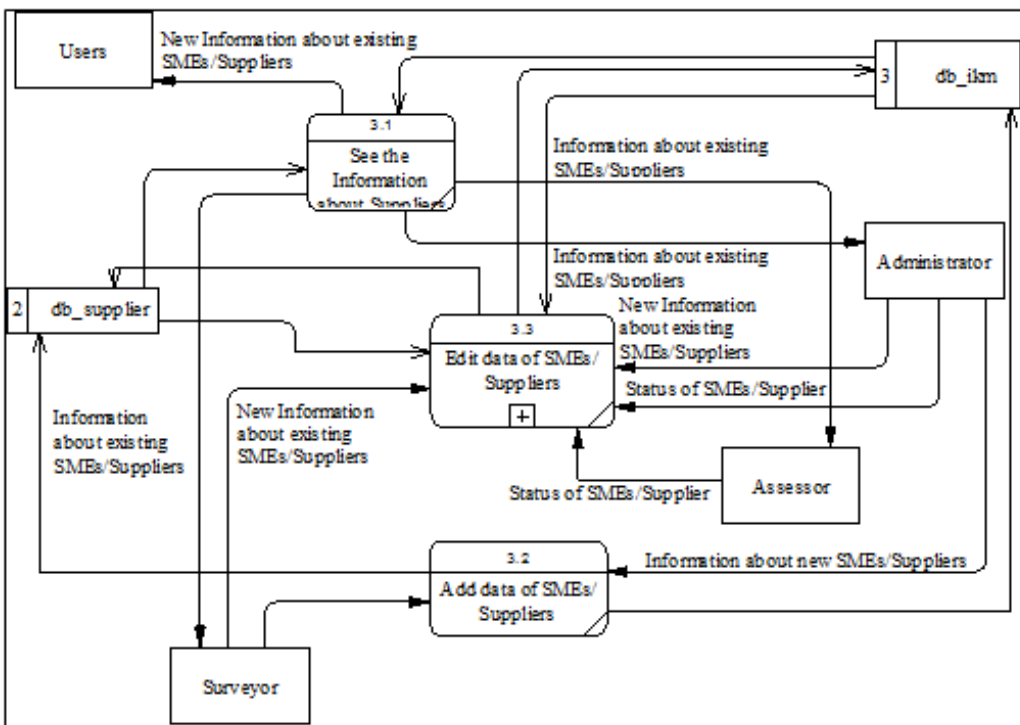

Figure 4. The DFD Level 2 of proposed a web-based decision support system

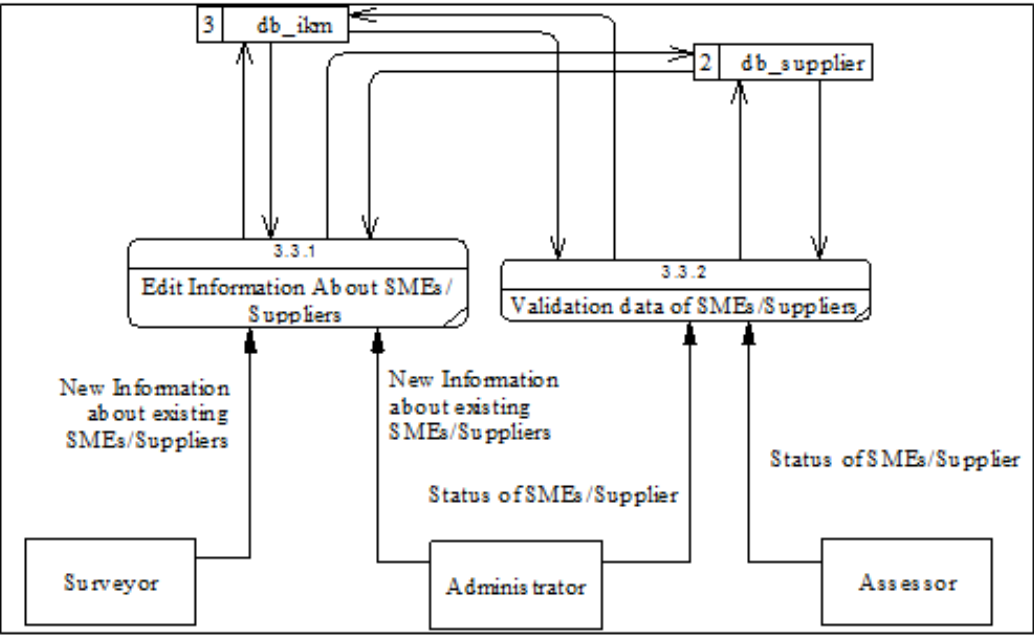

Figure 5. The DFD Level 3 of proposed information systems 
Thus, the ERD of the proposed a web-based decision support system can be seen in Fig. 6 .

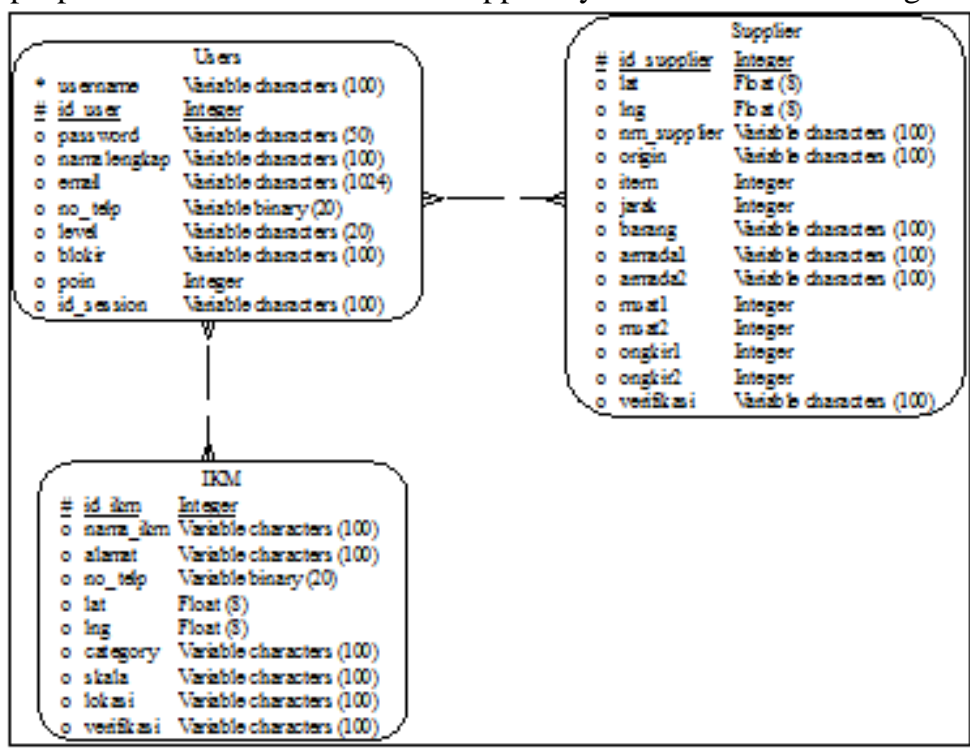

Figure 6. The ERD of proposed a web-based decision support system

\section{H. Interface Design}

The user interface is the aggregate of means by which people (the users) interact with a particular machine, device, computer program, or other complex tool (the thing). The user interface provides (the) means of: input, allowing the users to control the system; (and) Output, allowing the system to inform the users (feedback) (Deshmukh and Kaushik, 2013) Some display of user interface belongs to the GIS for supplier selection in batik industry can be seen in Fig 7 until Fig 10.

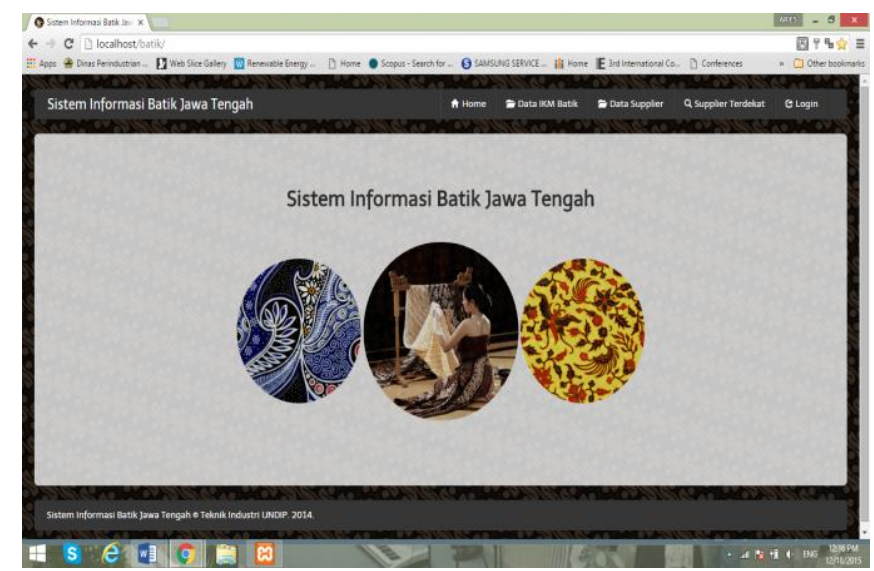

Figure 7. The interface of beginning application

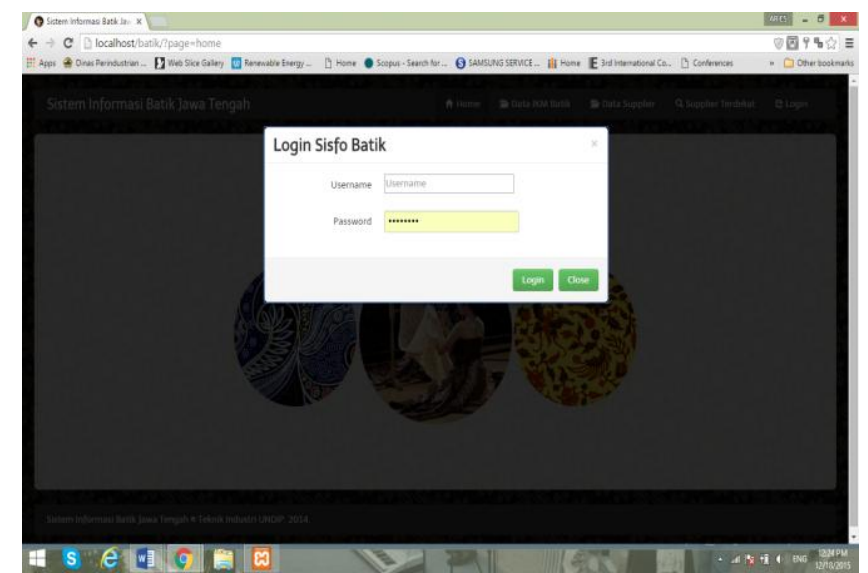

Figure 8. The interface for login to the application 


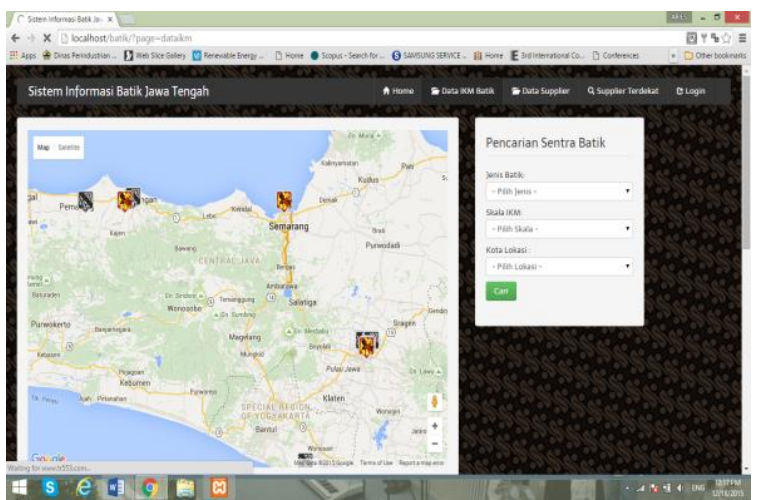

Figure 9. The interface for inputting data of location of SMEs

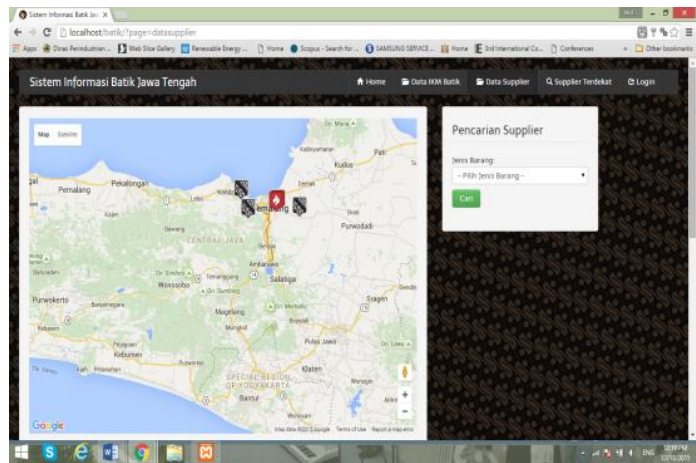

Figure 10. The interface for inputting data of location and raw material needed (type and amount)

\section{System Evaluation and Testing}

After the initial of prototype of a web-based decision support system was developed, the researchers conducted a comprehensive functional testing and evaluation. Functional testing is very common and lots of research is done on them in past that's why only in rare cases a site crashes due to lack of functional testing (Hooda, and Chhillar, 2015). There were to type of functional testing test used in this study to ensure the validity and reliability of the information system being develop, i.e. acceptance testing and, and system testing. The first, acceptance testing is performed mainly known as alpha and beta testing to ensure the customers are able to perform intended functionality and feedback is taken to further enhance quality of software. Alpha testing is conducted when any type of new software or version of old software is released. Alpha test involves the process of quality inspection of the information system design. Alpha testing is a type of acceptance testing performed by the developers under controlled environment at software development site. Usually, alpha testing are tested by some specific groups of users, those who are chosen by the software developer. They test and check whether all the features in the software that are provided work properly or not (Lawanna, 2012). Alpha testing is a kind of both black box as well as white box testing technique (Goel and Gupta, 2014). Additionally, alpha testing can also conduct by the gray box testing technique which is combination of black and white box techniques (Beizer, 1990). Beta testing is conducted after alpha testing. Beta testing is also known as pre-release testing. Versions of the software refer to beta versions that are released to limited groups of people. It can ensure the product has a few bugs or faults. Sometimes, beta versions are produced to the public to increase the feedback area and to increase the number of future users. Beta testing is a kind of black box testing technique. Fewer crashes and some bugs are expected in beta testing (Lawanna, 2012; Goel and Gupta, 2014). The second, system testing is related to test the overall system to ensure that it is behaving or functioning as intended and as specified in requirement document (Hooda, and Chhillar, 2015).

\section{1) Acceptance testing}

There were two type of acceptance testing used in this study, i.e. alpha testing and beta testing. Then, this study used black bock technique for alpha testing. Black box testing technique is based on the analysis of the specifications of a piece of software without reference to its internal working. The goal is to test how well the component conforms to the published requirement for the component. Black box technique only examines the fundamental aspect of the system. It makes sure that input is properly accepted and output is correctly produced (Pardeshi, 2013). Thus, there were four group of users (administrator, surveyor, assessor, and user) are chosen to conduct the alpha testing with black box technique. In detail, the result of those testing can be seen in table 1 . 
Using Geographic Information Systems to develop decision support system for supplier selection in..

Table 1. The Result of Alpha Testing with Black Box Testing Technique

\begin{tabular}{|c|c|c|c|c|c|}
\hline No & Group of users & Test Case & Test Case Decryption & Output & $\begin{array}{l}\text { Accordance with } \\
\text { the design? }\end{array}$ \\
\hline \multirow[t]{2}{*}{1.} & \multirow[t]{2}{*}{$\begin{array}{l}\text { Administrator/ } \\
\text { Surveyor/ } \\
\text { Assessor/User }\end{array}$} & \multirow[t]{2}{*}{ Login } & $\begin{array}{l}\text { Administrator/ } \\
\text { Assessor/User login to the } \\
\text { information system with correct } \\
\text { username and password }\end{array}$ & $\begin{array}{l}\text { Information system } \\
\text { display the homepage }\end{array}$ & $\begin{array}{l}\text { Accordance with } \\
\text { the design }\end{array}$ \\
\hline & & & $\begin{array}{l}\text { Administrator/ } \\
\text { Surveyor/ } \\
\text { Assessor/User login to the } \\
\text { information system with non- } \\
\text { correct username and password }\end{array}$ & $\begin{array}{l}\text { Return to login page } \\
\text { with an explanation for } \\
\text { the cause of failure }\end{array}$ & $\begin{array}{l}\text { Accordance with } \\
\text { the design }\end{array}$ \\
\hline 2. & $\begin{array}{l}\text { Administrator/ } \\
\text { Surveyor }\end{array}$ & $\begin{array}{l}\text { Add the data } \\
\text { about SMEs/ } \\
\text { Supplier }\end{array}$ & $\begin{array}{l}\text { Administrator/surveyor input the } \\
\text { data about new SMEs or supplier }\end{array}$ & $\begin{array}{l}\text { Table data of SMEs or } \\
\text { supplier is added with } \\
\text { the new data }\end{array}$ & $\begin{array}{l}\text { Accordance with } \\
\text { the design }\end{array}$ \\
\hline 3. & $\begin{array}{l}\text { Administrator/ } \\
\text { Surveyor/ } \\
\text { Assessor/User }\end{array}$ & $\begin{array}{l}\text { See or retrieve } \\
\text { the data about } \\
\text { SMEs/ } \\
\text { Supplier }\end{array}$ & $\begin{array}{l}\text { Administrator/surveyor / assessor / } \\
\text { user see the data about SMEs batik } \\
\text { based on its category (stamped- } \\
\text { batik/ hand-writing batik), scale of } \\
\text { enterprise (small/ medium/ or large } \\
\text { enterprise), and the location of } \\
\text { SMEs } \\
\text { (Pekalongan/Solo/Yogyakarta). } \\
\text { Administrator choose to see a } \\
\text { particular type of supplier } \\
\text { (fabric/dye/wax) }\end{array}$ & $\begin{array}{l}\text { Table data of SMEs } \\
\text { based on its category, } \\
\text { scale of enterprise, and } \\
\text { the location of } \\
\text { enterprise } \\
\text { Table data of particular } \\
\text { type of supplier }\end{array}$ & $\begin{array}{l}\text { Accordance with } \\
\text { the design } \\
\begin{array}{l}\text { Accordance } \\
\text { the design }\end{array}\end{array}$ \\
\hline 4. & $\begin{array}{l}\text { Administrator/ } \\
\text { Surveyor }\end{array}$ & $\begin{array}{lr}\text { Update } & \text { the } \\
\text { data } & \text { about } \\
\text { SMEs/supplier }\end{array}$ & $\begin{array}{l}\text { Administrator/surveyor changes the } \\
\text { data about SMEs or suppliers } \\
\text { Administrator/surveyor deletes the } \\
\text { data about SMEs or supplier }\end{array}$ & $\begin{array}{l}\text { Table data of SMEs or } \\
\text { supplier is updated } \\
\text { with the new data } \\
\text { The short message will } \\
\text { be appear on the } \\
\text { screen "are you sure to } \\
\text { delete this data? }\end{array}$ & $\begin{array}{l}\text { Accordance with } \\
\text { the design } \\
\text { Accordance with } \\
\text { the design }\end{array}$ \\
\hline 5. & $\begin{array}{l}\text { Administrator/ } \\
\text { Assessor }\end{array}$ & $\begin{array}{l}\text { Validate the } \\
\text { data about } \\
\text { SMEs/supplier }\end{array}$ & $\begin{array}{l}\text { Administrator/ assessor validates } \\
\text { the data about SMEs or suppliers }\end{array}$ & $\begin{array}{l}\text { The short message will } \\
\text { be appear on the } \\
\text { screen "validation } \\
\text { status has been } \\
\text { changed" }\end{array}$ & $\begin{array}{l}\text { Accordance with } \\
\text { the design }\end{array}$ \\
\hline
\end{tabular}

As seen in Table 1, the result of alpha testing with black-box technique indicates that the all functions contained in the web-based decision support system being developed have been running properly. In the other words, it can be said that all the functions of the application of supplier selection based on GIS in batik industry has been successfully used and did not experience an error; if there is an error, this is caused by users who do not provide right input. In this study, beta testing is carry out by giving some questionnaire to the twelve potential user. It can be said that this study use "closed beta" in which beta testing is done by a closed group of individuals. In detail, list of questionnaire and the answers from twelve of potential users can be seen in Table 2 .

Table 2. The Result of Beta Testing with Questionnaire Technique

\begin{tabular}{|l|l|l|l|l|l|}
\hline Questionnaire & \multicolumn{3}{|l|}{ Answer (\%) } & \multicolumn{3}{l|}{} \\
\cline { 2 - 6 } & 1 & 2 & 3 & 4 & 3 \\
\hline $\begin{array}{l}\text { Do you agree, if I say that the application GIS for supplier } \\
\text { selection in batik industry have a good user interface? }\end{array}$ & 0 & 0 & 8.33 & 25.00 & 66.67 \\
\hline $\begin{array}{l}\text { Do you agree, if I say that this application will make the SMEs } \\
\text { easy to get the information about supplier of raw material } \\
\text { which is located in Central Java and Yogyakarta? }\end{array}$ & 0 & 0 & 33.33 & 58.34 & 8.33 \\
\hline $\begin{array}{l}\text { Do you agree, if I say that features contained in the page of } \\
\text { location of SMEs make the SMEs easier to find the nearest } \\
\text { supplier or to find supplier with lower cost of transportation? }\end{array}$ & 0 & 0 & 16.66 & 58.34 & 25.00 \\
\hline $\begin{array}{l}\text { Do you agree, if I say that operationalize of this application is } \\
\text { easier to understand? }\end{array}$ & 0 & 0 & 16.66 & 50.00 & 33.33 \\
\hline $\begin{array}{l}\text { Do you agree, if I say that the application can help the SMEs to } \\
\text { make effective decision about their supplier? }\end{array}$ & 0 & 0 & 16.66 & 66.67 & 16.66 \\
\hline
\end{tabular}

Strongly disagree; 2: Disagree; 3: Neither agree nor disagree; 4: Agree; 5: Strongly agree

So, based on the percentage of answer of the twelve respondent, the result of user evaluation regarding the functionality of the application being developed were summarized as follows: (i) at least two third of respondent agree that the application has a good user interface; (ii) more than half of respondent agree that the application make the users can easily get the information about supplier of raw material which is located in Central Java and Yogyakarta; (iii) more than half of respondent agree that features contained in the page of location of SMEs make the users easier to find the nearest supplier or to find supplier with lower cost of 
transportation; (iv) half of respondents agree that operationalize of this application is easier to understand; and (v) two third of respondent agree that the application can help the SMEs to make effective decision about their supplier.

\section{2) System testing}

Testing the positional accuracy is used as a tool for testing the system. Positional accuracy probably the most obvious aspect of quality and evaluates how well the coordinate value of an object in the database relates to the reality on the ground. Testing of positional accuracy is carry out by comparing the coordinate system from GIS which is used in this application with the coordinate system from Global Positioning System (GPS). GPS is a satellite and ground-based radio navigation and location system that enables the user to determine very accurate locations on the surface of the Earth (Enan, 2015). More specific, testing of positional accuracy will be carry out by assessing the differences between the coordinate of selected starting and ending point from GIS with the coordinate of selected starting and ending point from GPS. The result of testing of positional accuracy can be seen in Table 3. There is no differences between the coordinate of selected starting and ending point from GIS with the coordinate of selected starting and ending point from GPS

Table 3. Result of testing of positional accuracy

\begin{tabular}{|l|l|l|}
\hline \multirow{2}{*}{ Comparison } & Coordinate System \\
\cline { 2 - 3 } & GIS (Google Maps) & GPS (Open Street map) \\
\hline Coordinate of starting point & S $-7,050907$ & S $-07^{\circ} 03.0544^{\prime}$ \\
& E 110.437833 & E $110^{\circ} 26.2700^{\prime}$ \\
\hline Coordinate of ending point & S -7.053547 & S $-07^{\circ} 03.2128^{\prime}$ \\
& E 110.430537 & E $110^{\circ} 25.8322^{\prime}$ \\
\hline Distance between starting and ending point & $1.2 \mathrm{~km}$ & $1.2 \mathrm{~km}$ \\
\hline
\end{tabular}

\section{Conclusion}

First, this study aims to analyze the requirements of batik industry on effective and powerful software to select their supplier effectively. Second, this study aims to design, build, and test a web-based decision support system that using GIS to select the best supplier for particular raw material. This study use prototype approach as a method for developing a web-based decision support system. There were four-step in developing a web-based decision support system. The first step is identifying the user's basic requirement. The second step is developing an initial prototype, and the third and fourth step is using the prototype and revising and enhancing the prototype. After the initial prototype of an information system was developed, this study use acceptance sampling with alpha and beta testing and also use system testing with positional accuracy testing as a tool for revising and enhancing the initial prototype. The result of alpha testing indicates that all the functions of the application of supplier selection based on GIS in the batik industry has been successfully used and did not experience an error; if there is an error, this is caused by users who do not provide right input. The result of beta testing can be summarized as follows: were summarized as follows: (i) at least two third of respondent agree that the application has a good user interface; (ii) more than half of respondents agree that the application makes the users can easily get the information about supplier of raw material which is located in Central Java and Yogyakarta; (iii) more than half of respondents agree that the features contained in the page of location of SMEs make the users easier to find the nearest supplier or to find a supplier with lower cost of transportation; (iv) half of respondents agree that operationalize of this application is easier to understand; and (v) two third of respondent agree that the application can help the SMEs to make an effective decision about their supplier. Thus, the result of positional accuracy testing indicates that there is no differences between the coordinate of selected starting and ending point from GIS with the coordinate of selected starting and ending point from GPS This study has some limitations. The first limitation relates to the study region, which only Province of Central Java and Yogyakarta. Therefore, the scope of web-based decision support system being developed in this study is very limited. Thus, future research should attempt to include the other study region, such as Province of East Java and West Java, or maybe, the future research may include all the provinces of Indonesia. So, this webbased decision support system not only can be used by the SMEs batik in the Province of Central Java and Yogyakarta, but also can be used by the SMEs located in the other province. The second limitation is related to the aspect that need to be considered in the design of web-based decision support system of supplier selection. In this case, the road and traffic condition have not been considered in the design of web-based decision support system for supplier selection. In this case, the road and traffic condition can influence the fuel consumption and lead time delivery, which in turn, it will be influenced the cost of delivery and also the number of inventories. Based on this condition, the future research should include the road and traffic condition as the important criteria for selecting the best supplier among several suppliers located near the SMEs. The third limitation is related with implementation of web-based decision support system for supplier selection among SMEs. Only several SMEs has been chosen for a sample to try the prototype of web-based decision support system being 
developed. It is necessary to make sure that proposed web-based decision support system for supplier selection can be used by SMEs batik. In this case, the government as a regulator, must encourage the SMEs uses the webbased decision support system for supplier selection through several policies such as conduct a training about using the software, provide some facilities (computers and the internet) which can be used by SMEs to run the application, and the other relevant policy. So, based on this condition, it is necessary for the future research to conduct a study about policies should be done by the government and, also design the indicator to measure the success of the implementation of that policy.

\section{Acknowledgements}

An acknowledgement section may be presented after the conclusion, if desired.( 8)

\section{References}

[1] J. Rezaei, SMEs and supply chain management: a functional perspective, Master Thesis, Science and Industrial Management, University of Tehran, Iran, 2012.

[2] H. Hanny, The urge of finding new venture capital regime for Indonesia. Master Thesis, International Business Law, Tilburg University, Austria, 2014

[3] B. Nooteboom, Innovation and diffusion in small firms: theory and evidence, Small Business Economics, 6(5), 1994, $327-347$.

[4] A. Gunasekaran, L. Forker, \& B. Kobu, Improving operations performance in a small company: a case study, International Journal of Operations \& Production Management, 20(3), 2000, 316-336.

[5] R. Davidrajuh, Automating supplier selection procedures. Dissertation, Narvik Institute of Technology, Narvik, Norway, 2001.

[6] C.C. Yang, \& B.S. Chen, Supplier selection using combined analytical hierarchy process and grey relational analysis, Journal of Manufacturing Technology Management, 17(7), 2006, 926-941.

[7] R. Verma, \& M.E. Pullman, An analysis of the supplier selection process, Omega, 26(6), 1998, 739-750.

[8] G.W. Dickson, An Analysis of Vendor Selection Systems and Decisions, Journal of Purchasing, 2(1), 1966 winter, 5-7

[9] Z. Zhang, J. Lei, N. Cao, K. To, \& K. Ng, Evolution of supplier selection criteria and methods. European Journal of Operational Research, 4(1), 2003, 335-342.

[10] C.A. Weber, J. R. Current, \& W.C. Benton, Vendor selection criteria and methods. European journal of operational research, 50(1), 1991, 2-18.

[11] S.E. Fawcett, \& G.M. Magnan, Achieving world-class supply chain alignment: benefits, barriers, and bridges. Tempe, AZ: Center for Advanced Purchasing Studies, 2001

[12] W. Ho, X. Xu, \& P. K. Dey, Multi-criteria decision making approaches for supplier evaluation and selection: A literature review. European Journal of Operational Research, 202(1), 2010, 16-24.

[13] R. Mwikali, \& S. Kavale, Factors affecting the selection of optimal suppliers in procurement managemen,. International Journal of Humanities and Social Science, 2(14), 2012, 189-193.

[14] A. K. Kar, Revisiting the supplier selection problem: An integrated approach for group decision support. Expert systems with applications, 41(6), 2012, 2762-2771.

[15] B. M. Beamon, Measuring supply chain performance, International journal of operations \& production management, 19(3), 1999, 275-292.

[16] J. M. Kibe, Application of inventory manufacturing practices. a survey in large manufacturing firms in Kenya. Unpublished MBA Project University of Nairobi, 2000

[17] R. Jain, A.R, Singh, \& P.K. Mishra, Prioritization of supplier selection criteria: A fuzzy-AHP approach, MIT International Journal of Mechanical Engineering, 3(1), 2000, 34-42.

[18] D.J. Cowen, GIS versus CAD versus DBMS: What are the differences? Photogram, Eng. Remote Sens., 54(11), 1988, 1551-1555.

[19] J. Star, \& J, E. Estes, Geographic information systems: an introduction (Vol. 303). Englewood Cliffs, NJ: Prentice Hall, 2000

[20] T. Christiansen, Geographical information systems for regional rural development projects in developing countries: potential and limitations of an innovative technology for the planning and management of a special type of technical cooperation project (Vol. 75). Geograph. Inst, 1998

[21] M. H. B. Selamat,., M. S. B. Othman, A. F. B. Hassan, N. I. B. M. Zukepli, N. H. B. M Shamsuddin, A.B. Selamat, \& L.B.M. Yusuf, A review on application of geographical information system in town planning in Malaysia, 2012

[22] B.E. Mennecke, Understanding the role of geographic information technologies in business: applications and research directions, Journal of Geographic Information and Decision Analysis, 1 (1), 2000, 44-68

[23] P.A. Longley, M.F. Goodchild, D.J. Maguire, \& D.W. Rhind, Geographical Information Systems, Second Edition, John Wiley \& Sons, New York, N.Y, 1999

[24] Z.R, Peng, \& M.H. Tsou, Internet GIS: distributed geographic information services for the internet and wireless networks. John Wiley \& Sons, 2003

[25] T.E. Chow, The potential of maps APIs for internet GIS applications. Transactions in GIS, 12(2), 1999, 179-191.

[26] J.A.S. Gomez, GIS applications for real estate in Honduras, Master Thesis, International Master Program for Environment Sustainable Development, 1999

[27] J. Udell, Beginning Google Maps mashups with mapplets, KML, and GeoRSS: from novice to professional. A press, 1999

[28] J.D. Naumann, \& A. M. Jenkins, Prototyping: the new paradigm for systems development. Mis Quarterly, 1982, $29-44$.

[29] L. Bally, J. Brittan, \& K.H. Wagner, A prototype approach to information system design and development, Information \& Management, 1(1), 1977, 21-26.

[30] D. E. Avison, G. Fitzgerald, \& A.T. Wood-Harper, Information systems development: a tool kit is not enough. The Computer Journal, 31(4), 1988. 379-380.

[31] B.W. Boehm, A spiral model of software development and enhancement. Computer, 21(5), 1988, 61-72.

[32] S. Hekmatpour, \& D.C. Ince, Software prototyping, formal methods and VDM. Addison-Wesley, 1988

[33] K.E. Lantz, The prototyping methodology. Prentice-Hall, Inc., 1986

[34] K.C. Laudon, \& J.P. Laudon, Management information systems: managing the digital firm. New Jersey, 2004

[35] L.A. Ajah, \& J.O. Ugah, Comparative Analysis of Software Development Methodologies. International Journal of Advanced Research in Computer Science and Software Engineering, 3(6), 2013, 655-665 
[36] H. Eichelberger, Automatic layout of UML use case diagrams. In Proceedings of the 4th ACM symposium on Software visualization (pp. 105-114). ACM, 2008.

[37] A. Cockburn, Writing Effective Use Cases. AddisonWesley Longman Publishing Co. Inc., Boston, MA. 2000.

[38] S. K, Sharma \& S. Ojha, Online Examination Application using SAP ABAP, International Journal of Engineering, Business and Enterprise Applications, 8(2), 2000, 111-118

[39] J. W. Satzinger, R.B.Jackson, \& S.D. Burd, Systems analysis and design in a changing world. Cengage learning. Boston-USA, 2011

[40] F. Yakubu, B.I. Ahmad, O.M. Omowumi, \& M.A. Mngohol, Process and database modelling of a University Bursary system: a perspective of cash office, International Journal of Computer Science Issue, 8 (2), 2011, 555-560

[41] J.B. Dixit, \& R. Kumar, Structured system analysis and design. Paperback Ed. New Delhi, India: Laxmi Publisher, 2011

[42] R. Ibrahim, \& S.Y. Yen, An automatic tool for checking consistency between Data Flow Diagrams (DFDs). World Academy of Science, Engineering and Technology, 69, 2010

[43] Y. Tao, \& C. Kung, Formal definition and verification of data flow diagrams. Journal of Systems and Software, 16(1), $1991,29-36$.

[44] Z. Arsovski, D.R.,Petrovic, I., Milanovic, V. Rankovic, \& Z. Kalinic,. Measuring the data model quality in the e-supply chains. International Journal for Quality Research, 6(1), 2012

[45] P.P.S. Chen, The entity-relationship model - toward a unified view of data. ACM Transactions on Database Systems (TODS), 1(1), 2012, 9-36

[46] O. Deshmukh, \& M. Kaushik, An overview of software verification \&validation and selection process, International Journal of Computer Trends and Technology, 4(2), 2013, 177-182

[47] I. Hooda, \& R.S. Chhillar, Software test process, testing types and techniques. International Journal of Computer Applications, 111(13), 2015

[48] A. Lawanna, The theory of software testing. AU Journal of Technology, 16(1), 2012

[49] R. Goel, \& N. Gupta, Survey on acceptance testing technique. International Journal of Software and Web Sciences

[50] B, Beizer, Software testing techniques, Van Nostrand Reinhold. Inc, New York NY, 1990

[51] S.N. Pardeshi, Study of testing strategies and available tools. International Journal of Scientific and Research Publications, 2013, 2250-3153.

[52] N. M. Enan, Geographic information system as a tool management solution in Rwanda, East African Journal of Science and Technology, 5(1), 2015, 33-45 